\title{
LOSS OF CORRECTION AFTER VERTEBRECTOMY FOR TREATMENT OF SPINAL DEFORMITIES
}

\author{
PERDA DE CORRECÃO APÓS VERTEBRECTOMIA NO TRATAMENTO DE DEFORMIDADES DA \\ COLUNA VERTEBRAL
}

\section{PÉRDIDA DE CORRECCIÓN DESPUÉS DE VERTEBRECTOMÍA EN EL TRATAMIENTO DE DEFORMIDADES DE LA COLUMNA VERTEBRAL}

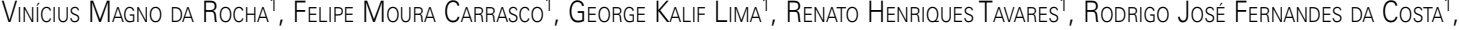 \\ luis Antônio Medeiros Moliterno ${ }^{1}$, Antônio Eulalio Pedrosa Araujo Junior ${ }^{1}$, Diego Pinheiro Aguiar ${ }^{1}$, André Luiz loyelo Barcellos ${ }^{1}$
}

1. Instituto Nacional de Traumatologia e Ortopedia Jamil Haddad - Ministry of Health (INTO/MS), Rio de Janeiro, RJ, Brazil.

\begin{abstract}
Objective: To evaluate the loss of correction after treatment of spine deformities with the technique of isolated posterior vertebrectomy. Methods: Twenty-one patients were followed-up for three years after surgery with panoramic X-rays, CT scans, SF-36 and Oswestry questionnaires. We evaluated the loss of correction, CAGE subsidence and the evolution of the pelvis-T1 angle during follow-up. The correlation among the radiographic changes and functional and quality of life scores was also assessed. Results: All patients had some degree of loss of correction and subsidence of CAGE, especially in the first year of follow-up. Such losses exerted negative impact on the function, pain and self-image of the patients. Factors such as the stiffness of the fusion mass and size of implant used appear to have contributed to the occurrence of subsidence, regardless of age and bone mineral density. Conclusions: The use of spacers with larger cross-sectional diameter and more rigid rods can reduce the overloading on the anterior column of Denis, reducing the subsidence and loss of correction. Additional stabilization strategies such as the use of orthoses postoperatively can also be useful, and should be evaluated in subsequent studies.
\end{abstract}

Keywords: Spinal diseases; Osteotomy; Subsidence.

\section{RESUMO}

Objetivo: Avaliar a perda de correção após o tratamento de deformidades da coluna vertebral pela técnica de vertebrectomia posterior isolada. Métodos: Vinte e um pacientes foram acompanhados durante três anos após o tratamento cirúrgico com radiografias panorâmicas, tomografias computadorizadas e através dos questionários SF-36 e Oswestry. Foram avaliadas perda de correção, subsidência do CAGE e evolução do ângulo pelve-T1 durante o acompanhamento. Também foi avaliada a correlação entre as alterações radiológicas e os índices funcionais e de qualidade de vida. Resultados: Todos os pacientes apresentaram algum grau de perda de correção e subsidência do espaçador intersomático, especialmente no primeiro ano de acompanhamento. Tais perdas exerceram impacto negativo sobre função, dor e autoimagem dos pacientes. Fatores como a rigidez da massa de artrodese e as dimensões do implante utilizado parecem ter contribuído com a ocorrência de subsidência, a despeito de faixa etária e densidade mineral óssea. Conclusões: O uso de espaçadores com maior diâmetro seccional e hastes mais rígidas podem reduzir a sobrecarga da coluna anterior de Denis, diminuindo a ocorrência de subsidência e perda de correção. Estratégias de estabilização adicionais, como o uso de órteses no pós-operatório também podem ser úteis, e devem ser avaliadas em estudos subsequentes.

Descritores: Doenças da coluna vertebral; Osteotomia; Subsidência.

\section{RESUMEN}

Objetivo: Evaluar la pérdida de corrección después del tratamiento de las deformidades de la columna vertebral mediante la técnica de vertebrectomía posterior aislada. Métodos: Veintiún pacientes fueron seguidos durante tres años después de la cirugía mediante radiografías panorámicas, tomografías computarizadas y con el uso de los cuestionarios SF-36 y Oswestry. Se evaluó la pérdida de la corrección, la subsidencia del CAGE y la evolución del ángulo pelvis-T1 durante el seguimiento. También se evaluó la corrección entre las alteraciones radiográficas y los índices funcionales y de calidad de vida. Resultados: Todos los pacientes presentaron algún grado de pérdida de corrección y subsidencia del espaciador intersomático, especialmente en el primer año de seguimiento. Estas pérdidas ejercen impacto negativo sobre la función, el dolor y la autoimagen de los pacientes. Factores como la rigidez de la masa de artrodesis y el tamaño del implante usado parecen haber contribuido a la aparición de subsidencia, independientemente de la edad y la densidad mineral ósea. Conclusiones: El uso de espaciadores con diámetro de la sección transversal mayor y barras más rígidas pueden reducir la sobrecarga de la columna anterior de Denis, reduciendo la ocurrencia de subsidencia y pérdida de la corrección. Las estrategias de estabilización adicionales, tales como el uso de ortesis en el postoperatorio también pueden ser útiles, y deben ser evaluadas en estudios posteriores.

Descriptores: Enfermedades de la columna vertebral; Osteotomía; Subsidencia.

Study conducted at Instituto Nacional de Traumatologia e Ortopedia Jamil Haddad - Ministry of Health (INTO/MS), Rio de Janeiro, RJ, Brazil. Correspondence: Rua Desembargador Izidro, 18 - Sala 912, Praça Saens Peña,Tijuca, Rio de Janeiro, RJ, Brazil. 20.521-160. viniciusmagnodarocha@ gmail.com 


\section{INTRODUCTION}

Rigid deformities of the vertebral column are a therapeutic challenge for surgeons. Even with the improvements in techniques and modern implants, full corrections are difficult to achieve, and complications are common. ${ }^{1}$ Different osteotomy techniques have been recommended for the treatment of rigid deformities. Of these, vertebral column resection (VCR), or vertebrectomy, is the one that allows the greatest degree of correction. ${ }^{1.2}$

In VCR, a segmental defect is created through the resection of one or more vertebrae, using a dual approach (anterior and posterior) or the posterior approach alone. ${ }^{2}$ It was Maclennan ${ }^{3}$ who, in 1922, inaugurated the VCR technique for apical resection of rigid curves in severe scoliosis. Bradford, ${ }^{4}$ in 1987, used osteotomies by the dual approach, achieving corrections of up to $50^{\circ}$ for each vertebra resected. In 2002, Suk et al. ${ }^{2}$ described VCR by the posterior approach alone (PVCR). Just as technically demanding, this procedure avoids violating the chest cavity, allowing three-dimensional corrections in a shorter surgical time, with comparable efficacy to that of VCR by the dual approach. ${ }^{1}$ PVCR is currently used in various pathologies of the vertebral column, ${ }^{5-8}$ aiming at a well-balanced spine, with correction of the deformity and/or decompression of any compromised neurological tissue. ${ }^{1}$ Likewise, maintenance of correction obtained with the procedure is a basic prerequisite for the good results of the treatment, as failure to maintain the correction can lead to impaired vertebral alignment, neurological deterioration, and reduced quality of life. ${ }^{9}$

Loss of correction after surgical treatment of spine deformities has been an object of study among researchers since the last century. ${ }^{10-12}$ Various studies have already investigated the phenomenon of loss of correction after subsequent arthrodeses, correlating the progression of the deformity with different factors, ${ }^{13.14}$ but until now, none have investigated the loss of correction after VCR in the treatment of deformities of the vertebral column.

The objective of this study is to assess the loss of correction after PVCR for the treatment of deformities of the vertebral column, and the consequences of this loss in terms of patients' quality of life.

\section{METHODS}

This is a retrospective cohort study conducted at the Instituto Nacional de Traumatologia e Ortopedia Jamil Haddad - Ministry of Health (INTO/MS). Clinical data and radiographic findings of patients submitted to PVCR in the period 2004 to 2014 were obtained from medical records and imaging exams, after obtaining approval from the Institutional Review Board (CAAE: 56634616.4.0000.5273). The criteria for selection of patients are shown in Table 1.

Table 1. Criteria for the selection of subjects.

\begin{tabular}{|c|c|}
\hline \multirow{5}{*}{ Inclusion Criteria } & $\begin{array}{c}\text { Diagnosis of congenital or idiopathic } \\
\text { kyphoscoliosis }\end{array}$ \\
\hline & $\begin{array}{c}\text { Submitted to VCRP*, with resection of one or } \\
\text { more vertebrae between T3 and T12 }\end{array}$ \\
\hline & $\begin{array}{c}\text { Risser's higher than } 2 \text { or closed triradiate } \\
\text { cartilage }\end{array}$ \\
\hline & Minimum follow-up of three years \\
\hline & $\begin{array}{c}\text { Posterior instrumentation exclusively with } \\
\text { pedicle screws }\end{array}$ \\
\hline \multirow{4}{*}{ Exclusion Criteria } & Previous surgery of the vertebral column \\
\hline & $\begin{array}{c}\text { Inclusion of cervical vertebrae or iliac crest in } \\
\text { the posterior instrumentation }\end{array}$ \\
\hline & $\begin{array}{l}\text { Surgical procedure performed in more than one } \\
\text { step }\end{array}$ \\
\hline & $\begin{array}{l}\text { A failure due to breakage of the implant or } \\
\text { loosening of the bolts }\end{array}$ \\
\hline
\end{tabular}

Twenty-one patients met the selection criteria and were included in the study. The surgical procedure used in the treatment of deformities was PVCR, as described by Suk et al. ${ }^{2}$ All the patients used a brace in the first three months after surgery.

The variables analyzed were: age and weight at the time of surgery, sex, skeletal maturity, neurological status, number of vertebrae resected, and levels instrumented and subjected to fusion; radiologically, the angle values of the principal and secondary curves, dimensions of the titanium spacer used, and dimensions of the vertebrae immediately adjacent to the PVCR were measured; the occurrence of subsidence of the spacer in adjacent vertebrae was also analyzed.

For the measurement of radiographic parameters, panoramic images obtained in orthostasis, in the anterior-posterior and lateral views, at different times: immediate pre-operative (images acquired on patient admission), postoperative before hospital discharge, and annually after the surgery. The angles of the principal and secondary curves in the coronal plane, and of the global kyphosis (T5 to T12), were evaluated individually by two spine surgeons using the Cobb method. ${ }^{15}$ The values were compared among themselves and in cases where a difference greater than 5 was observed between the evaluators, an additional measurement was taken by a third spine surgeon. The means between the measurements were obtained, and were considered the measurement values of the curves. Computed tomographies were used to evaluate the positioning of the implants and the occurrence of pseudoarthrosis, as well as for the dimensions of the spacer and study of subsidence. The correction rate $(\mathrm{CR})$ and the annual loss rates $\left(\mathrm{LCR}^{1}, \mathrm{TPS}^{2}{ }^{2}, \mathrm{LCR}^{3}\right)$ both for the main curve (LCR-P) and for the thoracic kyphosis (LCR-TK), were estimated using the formulas given in Figure 1.

Subsidence was evaluated in mid-sagittal computed tomography acquisitions. (Figure 2) The penetration of the spacer into the vertebral bodies immediately adjacent to the osteotomy site was measured linearly, in millimeters. The percentage of penetration was estimated considering the average height of the vertebral body, as equations and diagrams shown in Figure 1. The dimensions of the spacer, and its relationship to the adjacent end plates (RE/P) were evaluated in mid-sagittal and mid-coronal computed tomography acquisitions, as illustrated in Figure 1.

Pre- and postoperative neurological status was monitored using the Frankel scale ${ }^{16}$ with evaluations on admission, immediately postoperative, and annually after the surgery.

As parameters for evaluating of postoperative quality of life, the pelvic angle-T1 (P-T1 $\hat{A}$ ) was considered, measured annually, in panoramic radiographies of the spine in orthostasis ${ }^{17}$ (Figure 2). The Oswestry Disability Index $(\mathrm{ODI})^{18}$, Scoliosis Research Society (SRS)-320 ${ }^{19}$ and Short Form-36 (SF-36) ${ }^{20}$ questionnaires, taken at the end of the third year after surgery, were also considered.

The data collected were analyzed by the program SPSS (Statistical Package for the Social Sciences), version 22.0 and by the application Microsoft Excel 2013. All the discussions considered a significance level of 5\% (0.05).

\section{RESULTS}

The data are shown in Tables 2 and 3 . The age of the patients ranged from 11 to 56 years, with a mean of 19.14 years $(\delta=10.0$; $\mathrm{Cv}=0.53$ ). The sample presented one outlier (56 years) and with exclusion of this, the mean age dropped to 17.30 years $(\delta=$ 5.51; $C v=0.32$ ). For the subsequent analysis, this latter value was considered. No significant strong correlation was found between age and the other study variables by Pearson's linear and Spearman's order coefficients.

The distribution of the number of resected vertebrae ranged from 1 to 3, with an average of two vertebrae removed. The number of instrumented levels ranged from 5 to 15 , with a mean of 10.4 $(\delta=2.5 ; \mathrm{Cv}=0.24)$, the most frequent being instrumentation of 


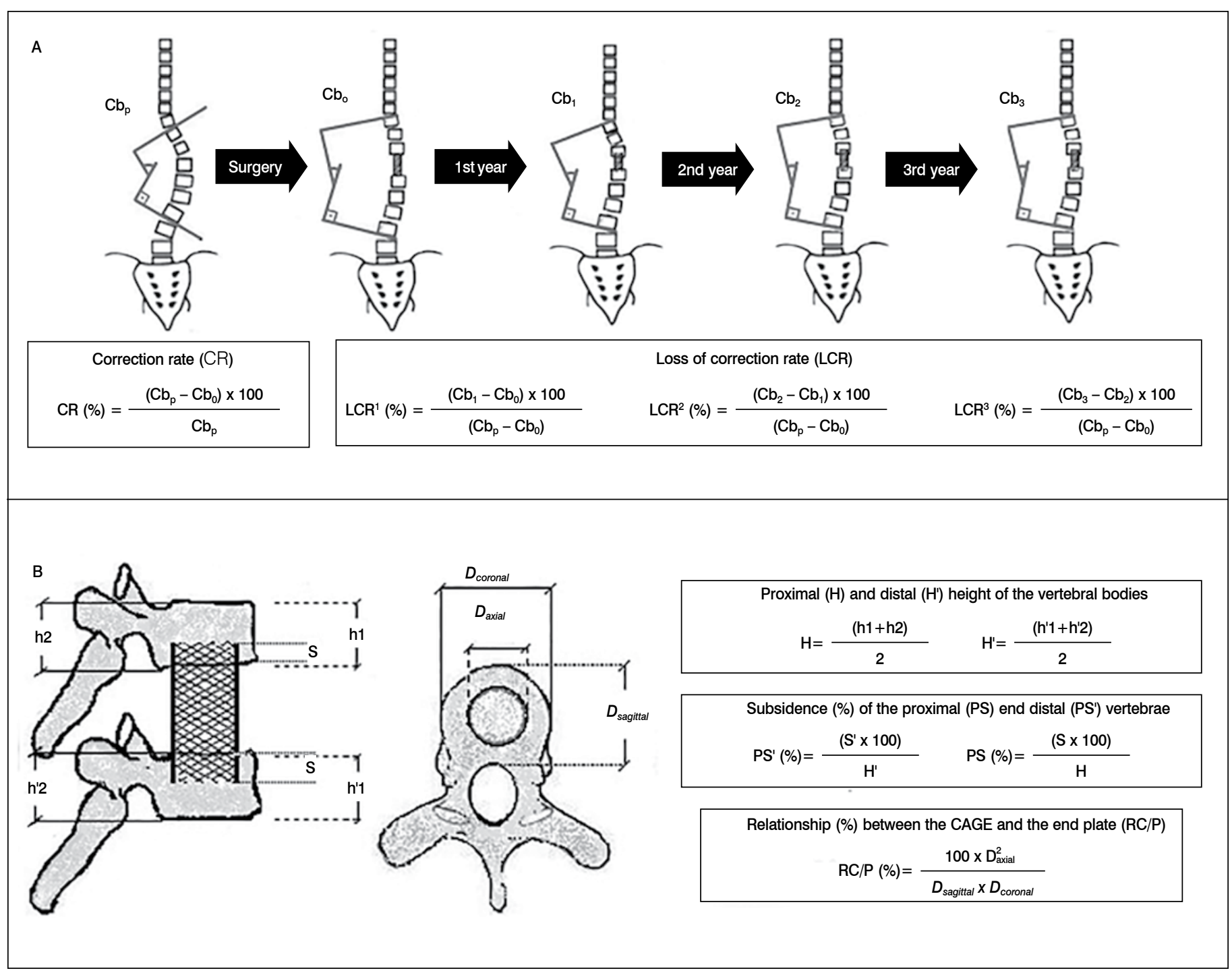

Figure 1. Diagrams and equations used in the measurement of radiographic parameters. (A) - Use of Cobb angles in the follow-up (Cbp - Pre-operative, $\mathrm{CbO}$ - Postoperative before discharge, Cb1 - 1 year postoperative, Cb2 - 2 years postoperative and Cb3 - 3 years postoperative) and equations used in the calculations of surgical correction rate (CR) and the annual rates of loss of correction (LCR ${ }^{1}, \mathrm{LCR}^{2}$ and $\mathrm{LCR}^{3}$ ). (B) - Measurement of subsidence of the spacer, where $\mathrm{h} 1$ and h'1 are the anterior heights of the vertebral bodies, and h2 and h'2 are the posterior heights; $\mathrm{H}$ and $\mathrm{H}$ ' are the mean heights of the vertebral bodies; $S$ and S' are the values of penetration of the spacer; PS and PS' are the percentages of subsidence of the spacer in relation to the mean height of the vertebral bodies; $D_{\text {axial }}, D_{\text {coronal }}$ and $D_{\text {sagittal, }}$, refer to the diameters of the spacer in those anatomical planes; and RE/P is the percentage ratio between the cross-section diameter of the spacer and the area of the lower end plate. In figure $1 \mathrm{~A}$, the diagram refers to the measurements made on panoramic radiographs; in Figure $1 \mathrm{~B}$, the diagram refers to the sagittal reconstructions and axial tomography images.

12 levels ( $f=38.1 \%)$. In all the subjects, the principal curve was thoracic, and the resected vertebrae were between T5 and T12. In the paired Student's t and Wilcoxon tests, the effect of surgical intervention was indisputable, with mean TCs of $54.4 \%$ in the coronal plane $(p<0.001)$ and $47.71 \%$ in the sagittal plane $(p<0.001)$.

Significant loss of correction was observed with a pattern of low variability $(C v=0.2)$ for the postoperative measurements, with a mean loss of correction rate in the coronal plane ( $\overline{\mathrm{LCR}}-\mathrm{P})$ of $22.3 \%$ in the first year, $6.2 \%$ in the second year and $2.8 \%$ in the third year ( $p$ values $<0.001$ in testing the paired Student's $t$ and Wilcoxon tests for each year). Significant loss of correction was also observed in the sagittal plane, with a pattern of low variability $(\mathrm{Cv}=0.2$ to 0.25$)$, at a loss of correction rate of kyphosis $\overline{\mathrm{LCR}}$-TK of $26.5 \%$ in the first year, $12.8 \%$ in the second year and $3.5 \%$ in the third year $(p<0.001$ in the paired Student's $t$ and Wilcoxon tests for each year). Figures 2 and 3 show the loss of correction in the coronal and sagittal planes during the follow-up period.

The correlation between the mean rate of mean correction
$(\overline{\mathrm{LCR}})$ in both planes and the number of vertebrae resected was not statistically significant by the Pearson's linear correlation tests ( $p=0.05$ for the coronal plane and $p=0.417$ for the sagittal plane) or Spearman's order correlation ( $p=0.129$ for the coronal plane and $p=0.451$ for the sagittal plane).

There was a proportional relationship between $\overline{\mathrm{LCR}}$ the $\overline{\mathrm{LCR}}-\mathrm{P}$ first and second years, with statistical significance by Pearson's coefficient $(p=0.005)$. The $\overline{\mathrm{LCR}}$ was higher in the first year, decreasing over the second and third years after surgery. The higher the $\overline{\mathrm{LCR}}-\mathrm{P}^{1}$ and $\overline{\mathrm{LCR}}-\mathrm{CT}^{1}$, the lower the loss observed in subsequent years. The variability with which these losses occurred, evaluated by the coefficient of variation was lower in the first year than in the other years, albeit with low statistical significance, regardless of the number of vertebrae removed. (Table 4) No statistical correlation was observed between the severity of the initial deformity, estimated by the preoperative Cobb measurements, and the loss of correction (Pearson's and Spearman's less than 0.4). 
Table 2. Evolution of the principal curve, thoracic kyphosis, and pelvis angle-T1.

\begin{tabular}{|c|c|c|c|c|c|c|c|c|c|c|c|c|c|c|c|c|c|}
\hline & Age & \multicolumn{2}{|c|}{ Preoperative } & \multicolumn{3}{|c|}{$\begin{array}{c}\text { Postoperative before } \\
\text { discharge }\end{array}$} & \multicolumn{3}{|c|}{$1^{\text {st }}$ Year Postoperative } & \multicolumn{3}{|c|}{$2^{\text {nd }}$ Year Postoperative } & \multicolumn{3}{|c|}{$3^{\text {rd }}$ Year Postoperative } & CL & $\mathrm{RE} / \mathrm{P}$ \\
\hline 1 & 56 & 78 & 88 & 32 & 40 & 24 & 44 & 55 & 16 & 48 & 60 & 14 & 48 & 60 & 14 & 4.5 & 34.5 \\
\hline 3 & 15 & 46 & 58 & 28 & 30 & 14 & 32 & 40 & 15 & 32 & 45 & 18 & 32 & 46 & 18 & 3.5 & 37.6 \\
\hline 4 & 14 & 62 & 57 & 32 & 30 & 23 & 38 & 42 & 24 & 40 & 46 & 25 & 42 & 48 & 25 & 2.5 & 31.4 \\
\hline 5 & 18 & 88 & 90 & 42 & 45 & 22 & 54 & 52 & 22 & 56 & 58 & 26 & 57 & 58 & 24 & 4.0 & 52.3 \\
\hline 7 & 13 & 84 & 50 & 34 & 30 & 20 & 47 & 39 & 18 & 50 & 42 & 20 & 52 & 44 & 18 & 5.5 & 36.7 \\
\hline 8 & 31 & 74 & 80 & 26 & 30 & 22 & 40 & 45 & 20 & 42 & 47 & 22 & 44 & 48 & 24 & 5.0 & 33.6 \\
\hline 9 & 21 & 82 & 70 & 44 & 50 & 20 & 51 & 55 & 16 & 53 & 60 & 14 & 54 & 61 & 14 & 3.0 & 46.6 \\
\hline 10 & 14 & 74 & 80 & 28 & 50 & 25 & 40 & 58 & 20 & 42 & 60 & 20 & 44 & 61 & 16 & 3.5 & 42.5 \\
\hline 11 & 16 & 64 & 100 & 30 & 50 & 25 & 37 & 62 & 20 & 40 & 64 & 20 & 42 & 65 & 20 & 4.5 & 47 \\
\hline 12 & 11 & 46 & 68 & 20 & 40 & 20 & 25 & 48 & 18 & 27 & 60 & 16 & 28 & 60 & 16 & 2.5 & 38.5 \\
\hline 16 & 11 & 80 & 80 & 40 & 45 & 16 & 48 & 49 & 16 & 50 & 50 & 18 & 52 & 52 & 16 & 3.5 & 58.9 \\
\hline 17 & 11 & 68 & 60 & 32 & 40 & 22 & 39 & 44 & 20 & 44 & 45 & 22 & 44 & 45 & 24 & 2.0 & 49.6 \\
\hline 18 & 17 & 78 & 90 & 32 & 55 & 16 & 44 & 63 & 14 & 46 & 66 & 18 & 47 & 67 & 14 & 4.5 & 47.6 \\
\hline 19 & 14 & 44 & 65 & 20 & 25 & 16 & 24 & 32 & 16 & 28 & 36 & 18 & 30 & 36 & 16 & 2.5 & 57.6 \\
\hline 20 & 20 & 78 & 65 & 35 & 25 & 22 & 38 & 35 & 20 & 44 & 38 & 22 & 44 & 39 & 24 & 5.0 & 44.3 \\
\hline 21 & 13 & 94 & 96 & 38 & 35 & 16 & 50 & 40 & 14 & 52 & 44 & 18 & 54 & 46 & 14 & 6.0 & 62.3 \\
\hline
\end{tabular}

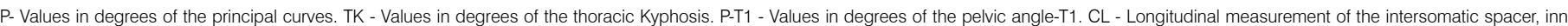

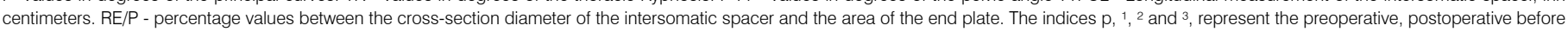
discharge, first, second and third years respectively.

Table 3. Oswetry, SRS-22 and SF-36 at the end of the third postoperative year.

\begin{tabular}{|c|c|c|c|c|c|c|c|c|}
\hline \multirow{2}{*}{\multicolumn{2}{|c|}{ ODI }} & \multicolumn{5}{|c|}{ SRS-22 } & \multicolumn{2}{|c|}{ SF-36 } \\
\hline & & \multirow{2}{*}{$\begin{array}{c}\text { Function } \\
4.4 \\
\end{array}$} & \multirow{2}{*}{$\begin{array}{l}\text { Pain } \\
4.3\end{array}$} & \multirow{2}{*}{$\begin{array}{c}\begin{array}{c}\text { Self- } \\
\text { Image }\end{array} \\
3.3 \\
\end{array}$} & \multirow{2}{*}{\begin{tabular}{|c|}
$\begin{array}{c}\text { Mental } \\
\text { health }\end{array}$ \\
3.6 \\
\end{tabular}} & \multirow{2}{*}{$\begin{array}{l}\text { Total } \\
3.9 \\
\end{array}$} & \multirow{2}{*}{$\begin{array}{c}\text { Physical } \\
49.7\end{array}$} & \multirow{2}{*}{$\begin{array}{c}\text { Mental } \\
54.8 \\
\end{array}$} \\
\hline 1 & 52 & & & & & & & \\
\hline 2 & 46 & 4.1 & 4 & 3.3 & 3.8 & 3.8 & 50.1 & 55.7 \\
\hline 3 & 14 & 3.6 & 3.7 & 3.3 & 3.6 & 3.6 & 40.1 & 55.3 \\
\hline 4 & 28 & 2.9 & 3 & 2.7 & 2.8 & 2.9 & 36.4 & 40.1 \\
\hline 5 & 22 & 3.1 & 3 & 3 & 3.6 & 3.2 & 37.8 & 49.8 \\
\hline 6 & 34 & 3.9 & 4 & 2.7 & 3.8 & 3.6 & 48.9 & 60.2 \\
\hline 7 & 26 & 4.1 & 4 & 3 & 4.5 & 3.9 & 50.3 & 64.3 \\
\hline 8 & 49 & 2.9 & 3 & 2.3 & 4 & 3.1 & 40.1 & 40.3 \\
\hline 9 & 25 & 4.3 & 4.3 & 4 & 3.6 & 4.1 & 59.8 & 54.8 \\
\hline 10 & 19 & 4.3 & 4.3 & 3.7 & 3.2 & 3.9 & 60.2 & 50.2 \\
\hline 11 & 21 & 3.7 & 3.7 & 2.7 & 2.8 & 3.2 & 52.3 & 48.6 \\
\hline 12 & 11 & 4.6 & 4.7 & 4 & 3.4 & 4.2 & 64.7 & 64.2 \\
\hline 13 & 50 & 4.3 & 4.3 & 4 & 3.2 & 4.0 & 57.5 & 58.9 \\
\hline 14 & 13 & 3.7 & 3.7 & 2.3 & 2.8 & 3.1 & 44.3 & 47.9 \\
\hline 15 & 22 & 4.7 & 4.7 & 4 & 2.8 & 4.1 & 59.3 & 51.4 \\
\hline 16 & 15 & 4.3 & 4.3 & 4.3 & 3.2 & 4.0 & 54.5 & 54.8 \\
\hline 17 & 19 & 3.7 & 3.7 & 3 & 2.8 & 3.3 & 39.6 & 54.2 \\
\hline 18 & 15 & 4.1 & 4 & 4.3 & 3 & 3.9 & 42.5 & 49.7 \\
\hline 19 & 11 & 3.9 & 4 & 4 & 4.5 & 4.1 & 38.7 & 64.2 \\
\hline 20 & 23 & 3.4 & 3.3 & 2.7 & 2.8 & 3.1 & 38.4 & 42.1 \\
\hline 21 & 13 & 4.3 & 4.3 & 4 & 4.5 & 4.3 & 42.6 & 66.8 \\
\hline
\end{tabular}

$\mathrm{ODI}$ - Values of the Oswetry Disability Index questionnaire. SRS-22 - Values of the scoliosis Research Society questionnaire, 22nd edition. SF-36 - Values of the 36-Item Short Form questionnaire.
Analyzing the first year after surgery, it is clear that this was the only period in which the loss of correction (LC) maintained a directly proportional relationship with the number of vertebrae resected, albeit with low statistical significance. (Figure 4)

The subsidence rate (SR) observed was, on average, $43.05 \%$ in the first year, $1.40 \%$ in the second year, and $0.89 \%$ in the third year. The difference between the rates was statistically significant between the years of follow-up ( $p=0.000$ by the Friedman test). (Figure 5 )

There was no significant correlation between SR and age or number of vertebrae resected $(p>0.05$ in the Pearson's and Spearman's correlation tests) in any of the three years of follow-up. The correlation between SR and the LCR was significant only during the first year after surgery. (Table 5)

Analyzing the dimensions of the spacer, we found a significant correlation of proportionality between its longitudinal measurement and CR $(p<0.001)$ and with the SR $(p<0.005)$. We also found a strong correlation between RE/P and the SR in the first year after surgery, with a correlation of -0.76 by Pearson's coefficient and -0.81 by Spearman's coefficient $(p<0.05)$.

In relation to neurological status, 17 patients (81\%) maintained their Frankel score after the surgery. Four patients had an improvement in status: one patient from Frankel $\mathrm{C}$ to Frankel $\mathrm{E}$, and three patients from Frankel $D$ to $E$ (14.3\%). There was no worsening of neurological symptoms, even in patients who already presented some deficit in the preoperative evaluation. The postoperative Frankel score was maintained throughout the follow-up period, in spite of the loss of correction observed.

The correlations between ODI and the loss of correction in the coronal and sagittal planes over the three years after surgery were not statistically significant $(p>0.05$ in the Pearson and Spearman tests). The correlation between ODI and age was positive $(p<0.05$ in the Spearman test). No significance was found in the linear regression model relating the LCR, age, and ODI. All the models proposed for the three years after surgery showed no statistical significance in parameters $(p>0.05)$, or significance of the model by the $F$ test $(p>0.05)$, and had low explanatory power $\left(R^{2}<0.3\right)$. 


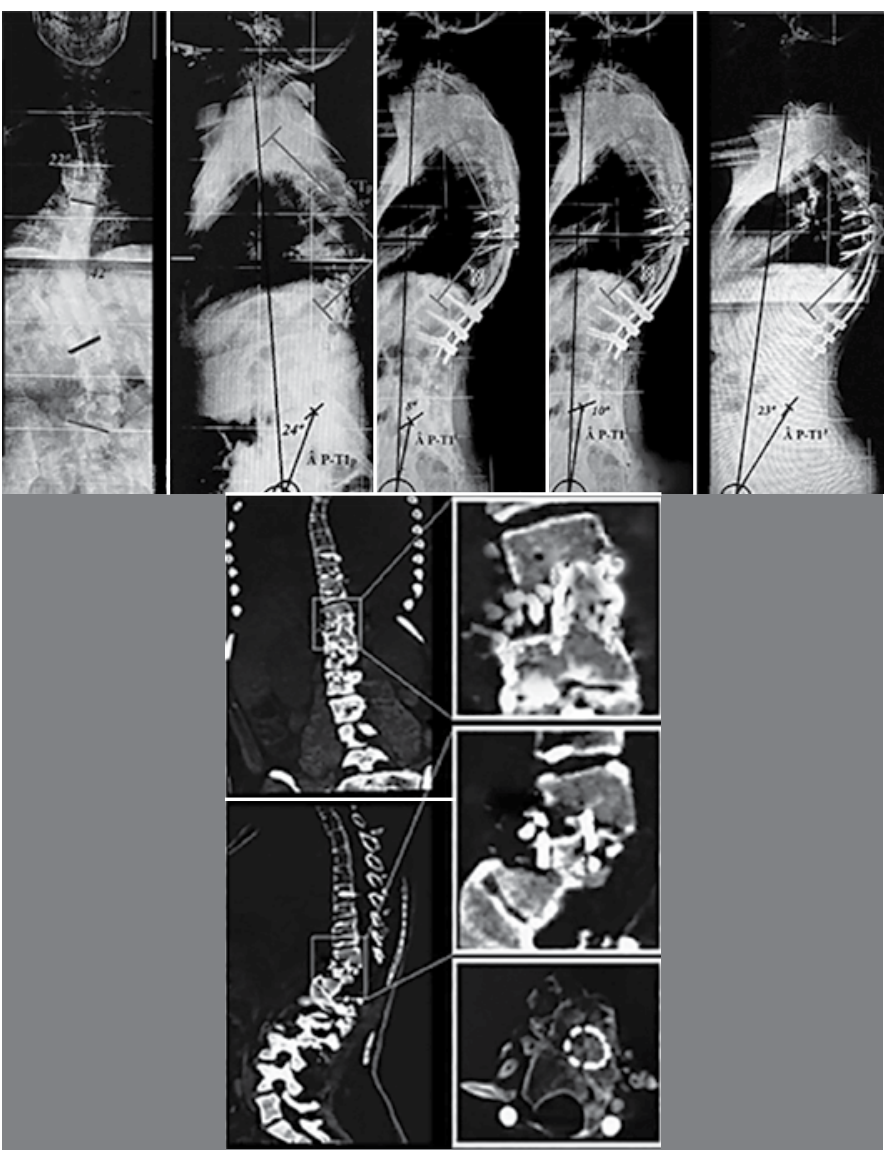

Figure 2. Imaging exams used in the follow-up of patients.

$\hat{A}$ P-T1 - pelvic angle-T1 measured in degrees. TK - thoracic kyphosis. The indices ${ }^{1}, 2$ and ${ }^{3}$, represent the first, second and third years respectively.

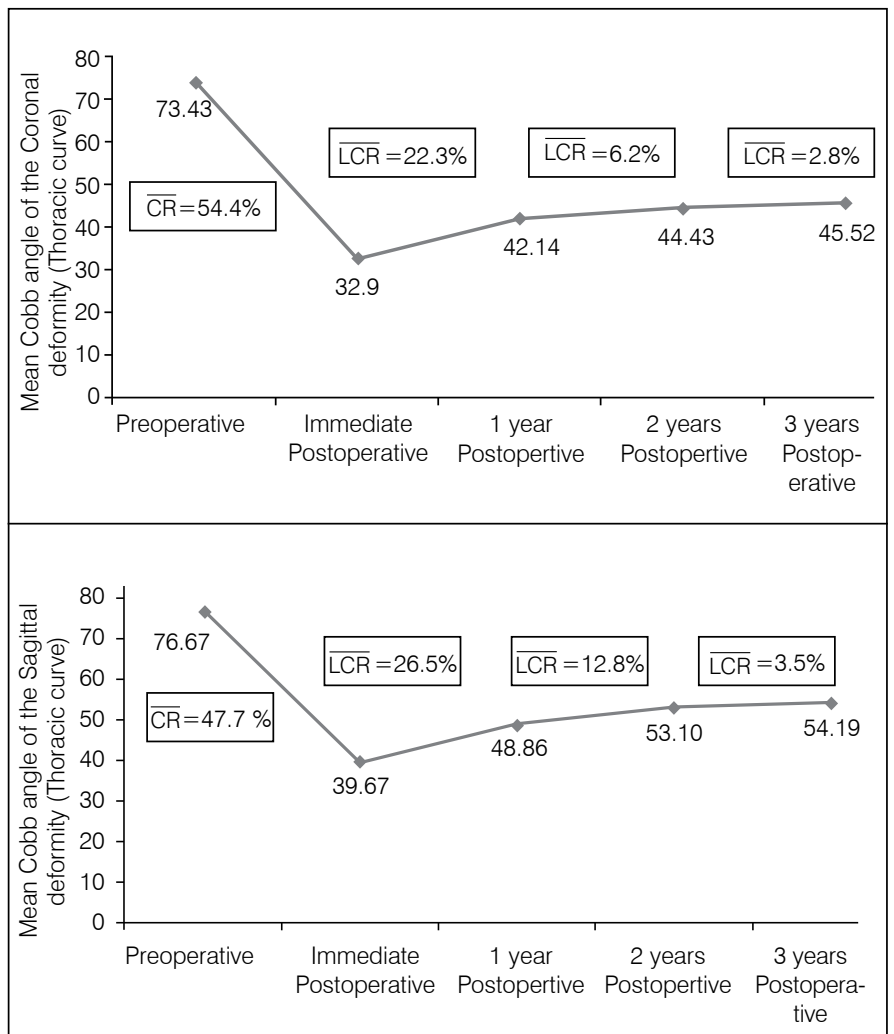

Figure 3. Evolution of the deformity in the postoperative period. CR -Average correction rate. $\overline{\mathrm{LCR}}$ - Mean loss of correction rate.
Table 4: Correlation of loss of correction rate and number of vertebrae resected.

\begin{tabular}{c|c|c}
\hline & $\begin{array}{c}\text { Pearson's Linear } \\
\text { Correlation }\end{array}$ & $\begin{array}{c}\text { Spearman's Order } \\
\text { Correlation }\end{array}$ \\
\hline$\overline{\mathrm{LCR}}-\mathrm{P}^{1}$ (p-valor) & 0.350 .116 & 0.280 .218 \\
\hline$\overline{\mathrm{LCR}}-\mathrm{TK}^{1}$ (p-valor) & 0.250 .282 & 0.230 .313 \\
\hline$\overline{\mathrm{LCR}}-\mathrm{P}^{2}$ (p-valor) & -0.250 .265 & -0.100 .677 \\
\hline$\overline{\mathrm{LCR}}-\mathrm{TK}^{2}$ (p-valor) & 0.070 .778 & 0.280 .212 \\
\hline$\overline{\mathrm{LCR}}-\mathrm{P}^{3}$ (p-valor) & -0.150 .522 & -0.110 .626 \\
\hline$\overline{\mathrm{LCR}}-\mathrm{TK}^{3}$ (p-valor) & 0.370 .102 & 0.400 .072 \\
\hline
\end{tabular}

LCR-p- Mean loss of correction rate of the principal curve. LCR-CT - Mean loss of correction rate of the thoracic kyphosis. The indices ${ }^{1},{ }^{2}$ and ${ }^{3}$. represent the first. second and third years respectively.

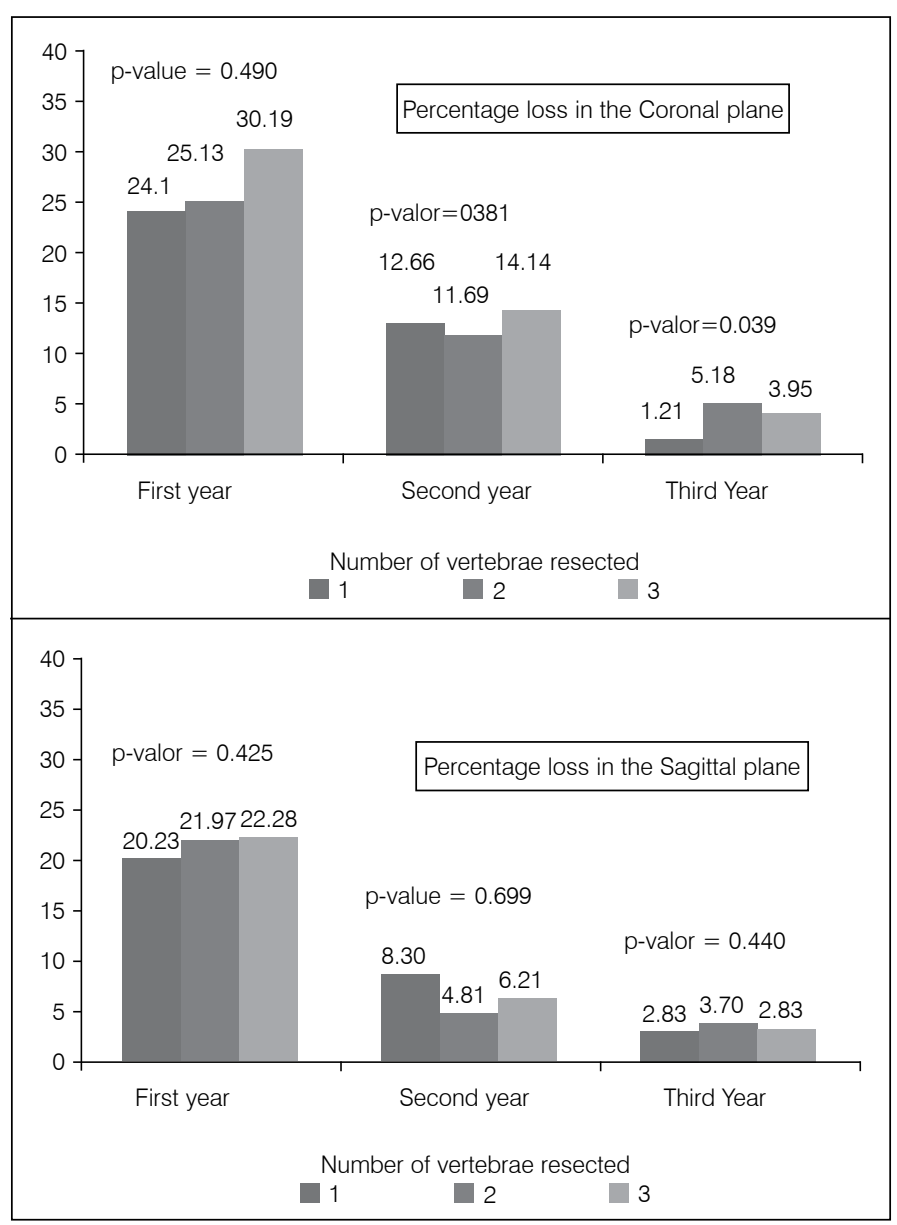

Figure 4. Loss of correction by the number of vertebrae resected.

P-T1 varied significantly in the postoperative period (Table 2) but showed no significant correlation with ODI or with the domain mental health of the SRS-22 ( $p>0.05$ in the Pearson and Spearman tests). However, a strong and statistically significant correlation was observed for the items function, pain, and self-image in this questionnaire (coefficients $>0.7, p<0.05$ ). Also, there was a significant correlation between SF-36 and P-T1, albeit weaker than those observed with SRS22 (Pearson -0.54 and Spearman -0.53, both with $p<0.05$ ).

\section{DISCUSSION}

Since the second half of the last century, the loss of correction after surgical treatment of deformities of the vertebral column has been an object of interest. Dubousset et al. ${ }^{11}$ were the first to report the progression of the deformity in patients submitted to posterior arthrodesis, inaugurating the research on the subject. ${ }^{10-13}$ For a long 


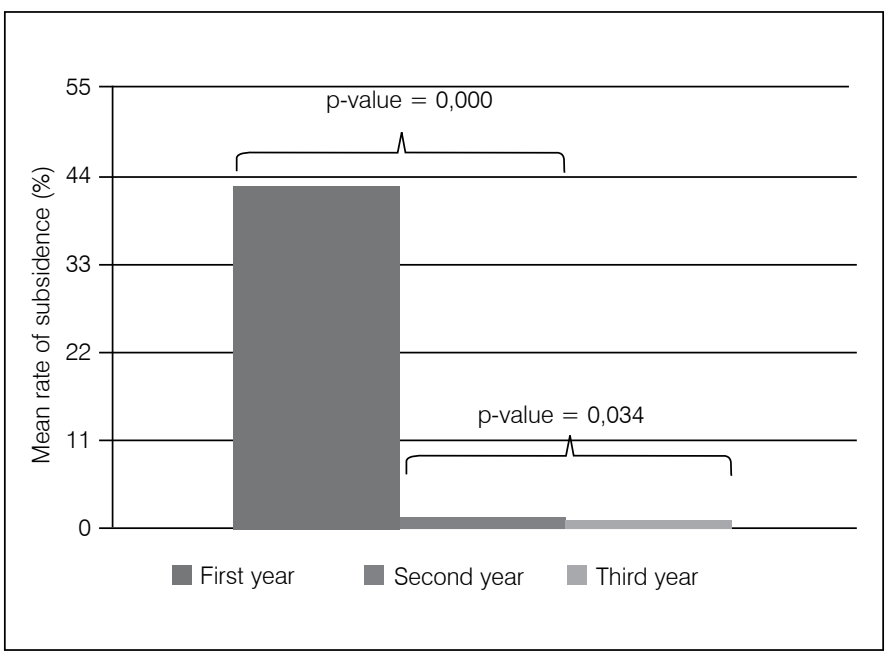

Figure 5. Rate of annual subsidence.

Table 5. Correlation between rate of subsidence and annual loss of correction rate.

\begin{tabular}{c|c|c}
\hline & $\begin{array}{c}\text { SR vs. LCR-P (Coronal } \\
\text { Loss) }\end{array}$ & $\begin{array}{c}\text { SR vs. LCR-CT } \\
\text { (Sagittal Loss) }\end{array}$ \\
\hline First Year & \multicolumn{2}{|l}{} \\
\hline Pearson's test & 0.16 & $0.75^{*}$ \\
\hline Spearman's test & 0.29 & $0.64^{*}$ \\
\hline Second Year & \multicolumn{2}{|}{} \\
\hline Pearson's test & -0.42 & 0.14 \\
\hline Spearman's test & -0.42 & 0.03 \\
\hline Third Year & \multicolumn{2}{|}{} \\
\hline Pearson's test & 0.03 & 0.13 \\
\hline Spearman's test & 0.2 & 0.13 \\
\hline
\end{tabular}

* significant correlation ( $p<0.001$ in the Pearson's and Spearman's tests) $\overline{\text { SR - Subsidence rate. LCR-P - Loss of correction rate of the principal curve. LCR-TK - Loss of }}$ correction rate of the thoracic kyphosis.

time, attention was focused on skeletal maturity, recommending that children with Risser's score of less than 2 be treated with anterior fusion to avoid loss of correction after surgery. ${ }^{10}$ With the advent of pedicle screws, it was believed that the better biomechanical control afforded by these implants would prevent the progression of the deformity even in the immature skeleton. However, this theory has not been born out in clinical case studies. ${ }^{13}$

Subsequent studies demonstrated that even patients treated after skeletal maturity with pedicle instrumentation and posterior fusion presented some degree of loss of correction, reinforcing the hypothesis that other factors are also involved in the loss of correction, besides skeletal growth. ${ }^{13}$ These factors were: the occurrence of pseudoarthrosis or implant failure, incorrect selection of levels of fusion, the phenomenon of adding-on and the biological plasticity of the arthrodesis mass. ${ }^{13,14,21,22}$ In our series, we included only patients instrumented exclusively with pedicle screws, Risser's score above 2, and/or closed triradiate cartilage, in order to reduce the interference of the growth of the anterior spine. All the patients underwent arthrodesis of the most stable vertebra proximal to the most stable distal vertebra, without any adding-on or pseudoarthrosis in any of the patients. Meanwhile, subsidence of the intersomatic spacer and progression of the deformity were observed in all patients.

Subsidence has been related to loss of correction and post-operative complications in other clinical scenarios, ${ }^{23}$ but not after PVCR. One of the factors directly related to the subsidence is bone mineral density (BMD). Patients with low BMD secondary to neoplastic di- seases and/or metabolic disorders, or those with dementia, have lower resistance at the interface between the spacer and the end plates, favoring the occurrence of the phenomenon. In our series, no study was done directly based on BMD, but none of the patients had conditions known to be related to bone fragility.

Regardless of age, the $\overline{\mathrm{LCR}}$ and the $\overline{\mathrm{SR}}$ maintained a relationship between themselves and were predominantly higher in the first year. We believe that during this period, the arthrodesis mass still has sufficient plasticity for the deformation, similar to what occurs in the process of fracture consolidation. During bone consolidation, the formation of a primary callus occurs during the first 3 to 5 weeks, but the trabecular structuring of the bone, which makes it capable of full load bearing, may extend from six months to one year. ${ }^{24}$ When a PVCR is performed, the segmental defect created with the resection of vertebral bodies is filled by the spacer with a bone graft. This implant is positioned in the anterior column, according to the classification of Denis, a region subject to compression. The maturation of the neoformed bone ensures sufficient rigidity to the arthrodesis mass, allowing compression forces to be dissipated, as they are shared between the spacer and the bone bridge. Given that the maturation of the arthrodesis may continue for up to a year, ${ }^{25}$ the biomechanical stress on the spacer during the first months after surgery may explain the higher SR observed during this period.

A variation of the PVCR technique, with the use of fragments of the costal arches posteriorly between the immediately adjacent vertebral laminae, is an attempt to increase the rigidity of the vertebrectomia, ${ }^{26}$ but further studies are needed to evaluate its true biomechanical importance. Another strategy that can decrease the occurrence of subsidence after the PVCR is the use of braces in the postoperative period. In our case series, all patients used braces for the first three months after surgery, to reduce the action of compressive forces on the Denis' anterior column, providing additional stabilization of the surgical implants, but LC and subsidence invariably occurred. Similarly, controlled studies evaluating the use of an external brace after surgery will also help to determine whether this strategy is ineffective or merely underused.

Another fact that corroborates the importance of consolidation and rigidity of the anterior arthrodesis mass is the fact that longer spacers are related to higher SP (\%). Two factors may explain these findings. Firstly, the length of the spacer requires the use of a larger amount of autologous graft, and therefore, a larger area for consolidation. Although the exact time of consolidation has not been determined in our study, we estimate that the area of arthrodesis through the formation of a bone bridge, and the time needed for this, are directly proportional. In addition, CR was related to the length of the spacer used, and not with the number of vertebrae resected or the number of levels instrumented. It is known that rigid and/or long curves require more stabilization by the implants used, both for pedicle screws and rods, and for intersomatic spacers. ${ }^{27}$ It is likely that the greater correction observed with the use of longer spacers has submitted the interfaces of this implant with the end plates to greater biomechanical stress, thus favoring the occurrence of subsidence. The SR was also greater in patients with a lower RE/P, possibly because the compression strength of the spacer is concentrated in a smaller area of end plate, favoring subsidence. In our study, we used titanium rods of $5.5 \mathrm{~mm}$ in diameter, which present a significant deformation coefficient. ${ }^{27.28}$ The use of larger-diameter rods and/or rods manufactured with more resistant alloys could add greater rigidity to the posterior stabilization, reducing the compression forces on the anterior column, where the spacer is positioned.

Another aspect that requires discussion is the fact that the patients who presented higher $\mathrm{LCR}^{1}$ also presented lower TPS ${ }^{2}$ and $\mathrm{LCR}^{3}$, regardless of the size of the spacer. We believe that for a single patient, during the period in which the arthrodesis has 
not acquired sufficient rigidity to withstand the compression loads without deforming, subsidence will occur until a new biomechanical equilibrium is established between the curvatures of the axial skeleton, especially in the sagittal plane. The exact moment during the first year after surgery when the speed of progression of the spacer decreases was not determined in this study and could, in conjunction with direct analyses of consolidation and BMD, contribute to an understanding of the dynamics of migration of the spacer in response to the plasticity of the arthrodesis. Equally, biomechanical studies involving the distribution of loads on Denis' anterior column, changes in the sagittal axis and its relationship with the spinopelvic alignment, would contribute greatly to the understanding of the process of adaptation of the skeleton to the VCPR technique.

We also assessed the impact of the LC with an increase in the coronal deformity on the patients' neurological status. Zhang and Miladi correlated thoracic kyphosis with neurological deterioration, relating the mechanical compression of the neuronal tissue and damage to the anterior vascularization of the spinal cord, as possible causes of this complication. ${ }^{29.30}$ During the follow-up period of our patients, there was no neurological deterioration. We understand that resection of the posterior elements in the PVCR technique provides additional protection by enabling the posterior deviation of the spinal cord when the loss of correction occurs gradually. In addition, it is expected that gradual recurrence of the deformity will allow the blood flow to the spinal cord to be diverted to alternative vascular supply routes, such as the branches of the anterior spinal artery.

Another focus of interest of our study was to evaluate how the LC would be capable of impacting the patients' functional capacity. Previous studies have suggested that subsidence can interfere in the curvature of the spine, and therefore, on pelvic balance - a prognostic marker that is increasingly used in the treatment of pathologies of the vertebral column. ${ }^{17.31}$ We opted for the use of P-T1ÂA as andicator of sagittal balance, and found that increasing values of this parameter after surgery were correlated with poorer scores for function, pain and self-image in the SRS-22. This estimated functional deterioration cannot be attributed directly to the PC, because the design of our study did not include the possibility of other determinant variables of spinopelvic equilibrium, such as the characteristics of the compensatory curves, or lumbar lordosis. Even so, as in our series the greatest $\overline{\mathrm{LCR}}$ variation $\overline{\mathrm{P}-\mathrm{T} 1 \hat{\mathrm{A}}}$ occurred during the first year, the impact of LC on the pelvic parameters cannot be overlooked, and should be evaluated in subsequent studies.

Our study is the first to evaluate the role of the phenomenon of subsidence in loss of correction after PVCR. It presents as limitations the small number of our sample, the lack of a direct evaluation of BMD or of the process of consolidation, and a biomechanical analysis of the forces acting on the spacer before and after maturation of the arthrodesis mass. We sought to analyze the phenomenon of subsidence by isolating confounding variables, such as skeletal maturity, type of implant and complications that could lead to PC, but we recognize that in view of the specific characteristics of the PVCR technique, the behavior of the complementary curves, and their relationship with the spinopelvic alignment, are not yet fully understood, prompting research in major centers around the world.

\section{CONCLUSION}

The phenomenon of subsidence after PVCR for the treatment of rigid deformities of the vertebral column is very prevalent, contributing greatly to LC in the postoperative period. Factors such as the plasticity of the arthrodesis, the length of the CAGE, and its smaller diameter, are related to a higher occurrence of the phenomenon, and should be taken into consideration. The use of spacers with larger diameters and/or more right rods can decrease the occurrence of subsidence and loss of correction. Complementary strategies to surgical stabilization, as the use of a brace, especially in the first year after surgery, can also be useful and should be evaluated in subsequent studies.

All authors declare no potential conflict of interest concerning this article.

CONTRIBUTIONS OF THE AUTHORS: Each author made a significant individual contribution to the development of the manuscript. VMR was responsible for the writing of the manuscript. FMC and GKL performed the data search in the medical records and image files. VMR, RHT, RJFC, AEPAJ, ALLB, and LAMM performed the surgeries and follow-up of patients, and also produced the clinical-imaging documentation. VMR and DPA performed the literature search, data processing and biostatistical analyses. ALLB conducted a review of the manuscript and contributed to the intellectual concept of the study. All the authors contributed to the intellectual concept of the study.

\section{REFERENCES}

1. Yang C, Zheng Z, Liu H, Wang J, Kim YJ, Cho S. Posterior vertebral column resection in spinal deformity: a systematic review. Eur Spine J. 2015 Jan 20. [Epub ahead of print]

2. Suk SI, Kim JH, Kim WJ, Lee SM, Chung ER, Nah KH. Posterior vertebral column resection for severe spinal deformities. Spine (Phila Pa 1976). 2002;27(21):2374-82.

3. MacLennan A. Scoliosis. BMJ. 1922:2:864-6.

4. Bradford D. Vertebral column resection. Orthop Trans. 1987;11:502.

5. Zhao H, ZhuY, Qiu GX, Zhang JG, Tian Y, Li SG. Single-stage posterior vertebrectomy with reconstruction in treatment of spinal tumor. ZhonghuaYi Xue Za Zhi. 2009:89(9):597-600.

6. Singh K, Samartzis D, An HS. Neurofibromatosis type I with severe dystrophic kyphoscoliosis and its operative management via a simultaneous anterior-posterior approach: a case report and review of the literature. Spine J. 2005;5(4):461-6.

7. Yang $\mathrm{BH}$, Li HP, He XJ, Zhao B, Zhang $\mathrm{C}$, Zhang T, et al. Total vertebral column resection combined with anterior mesh cage support for the treatment of severe congenital kyphoscoliosis. Zhongguo Gu Shang. 2014;27(5):358-62.

8. Dreimann M, Viezens L, Hoffmann M, Eicker SO. Retrospective feasibility analysis of modified posterior partial vertebrectomy with 360-degree decompression in destructive thoracic spondylodiscitis. Acta Neurochir (Wien). 2015;157(9):1611-8.

9. Kim SS, Cho BC, Kim JH, Lim DJ, Park JY, Lee BJ, et al. Complications of posterior vertebral resection for spinal deformity. Asian Spine J. 2012:6(4):257-65.

10. Hefti FL, McMaster MJ. The effect of the adolescent growth spurt on early posterior spinal fusion in infantile and juvenile idiopathic scoliosis. J Bone Joint Surg Br. 1983;65(3):247-54
11. Dubousset J, Herring JA, Shufflebarger H. The crankshaft phenomenon. J Pediatr Orthop. 1989:9(5):541-50.

12. Lee CS, Nachemson AL. The crankshaft phenomenon after posterior Harrington fusion in skeletally immature patients with thoracic or thoracolumbar idiopathic scoliosis followed to maturity. Spine (Phila Pa 1976). 1997;22(1):58-67.

13. Upasani W, Hedequist DJ, Hresko MT, Karlin LI, Emans JB, Glotzbecker MP. Spinal deformity progression after posterior segmental instrumentation and fusion for idiopathic scoliosis. J Child Orthop. 2015;9(1):29-37.

14. Mullaji AB, Upadhyay SS, Luk KD, Leong JC. Vertebral growth after posterior spinal fusion for idiopathic scoliosis in skeletally immature adolescents. The effect of growth on spinal deformity. J Bone Joint Surg Br. 1994;76(6):870-6.

15. Cobb JR. Outline for the study of scoliosis. Instr Course Lect. 1948;5:261-75.

16. Frankel HL, Hancock DO, Hyslop G, Melzak J, Michaelis LS, Ungar GH, et al. The value of postural reduction in the initial management of closed injuries of the spine with paraplegia and tetraplegia. I. Paraplegia. 1969:7(3):179-92.

17. Protopsaltis T, Schwab F, Bronsard N, Smith JS, Klineberg E, Mundis G, et al. TheT1 pelvic angle, a novel radiographic measure of global sagittal deformity, accounts for both spinal inclination and pelvic tilt and correlates with health-related quality of life. J Bone Joint Surg Am. 2014;96(19):1631-40.

18. Fairbank JC, Couper J, Davies JB, O'Brien JP. The Oswestry low back pain disability questionnaire. Physiotherapy. 1980;66(8):271-3 
19. Asher M, Min Lai S, Burton D, Manna B. The reliability and concurrent validity of the scoliosis research society-22 patient questionnaire for idiopathic scoliosis. Spine (Phila Pa 1976). 2003;28(1):63-9.

20. Patel AA, Donegan D, Albert T. The 36-item short form. J Am Acad Orthop Surg 2007;15(2):126-34.

21. Cho RH, Yaszay B, Bartley CE, Bastrom TP, Newton PO. Which Lenke $1 A$ curves are at the greatest risk for adding-on... and why? Spine (Phila Pa 1976). 2012;37(16):1384-90.

22. Risser JC, Norquist DM, Cockrell BR Jr, Tateiwa M, Hoppenfeld S. The effect of posterior spine fusion on the growing spine. Clin Orthop Relat Res. 1966;46:127-39.

23. Chen Y, Chen D, Guo Y, Wang X, Lu X, He Z, et al. Subsidence of titanium mesh cage: a study based on 300 cases. J Spinal Disord Tech. 2008;21(7):489-92.

24. Bigham-Sadegh A, Oryan A. Basic concepts regarding fracture healing and the current options and future directions in managing bone fractures. Int Wound J.2015:12(3):238-47.

25. Boden SD. Biology of lumbar spine fusion and use of bone graft substitutes: present, future, and next generation. Tissue Eng. 2000;6(4):383-99.

26. Lenke LG, Sides BA, Koester LA, Hensley M, Blanke KM. Vertebral column resection for the treatment of severe spinal deformity. Clin Orthop Relat Res. 2010:468(3):687-99.

27. Demura S, Murakami H, Hayashi H, Kato S, Yoshioka K, Yokogawa N, et al. Influence of Rod Contouring on Rod Strength and Stiffness in Spine Surgery. Orthopedics. 2015;38(6):e520-3.

28. Dick JC, Bourgeault CA. Notch sensitivity of titanium alloy, commercially pure titanium, and stainless steel spinal implants. Spine (Phila Pa 1976). 2001;26(15):1668-72.

29. Zhang Z, Wang H, Liu C. Compressive myelopathy in severe angular kyphosis: a series of ten patients. Eur Spine J. 2015 Jun 7. [Epub ahead of print]

30. Miladi L. Round and angular kyphosis in paediatric patients. Orthop Traumatol Surg Res. 2013;99(Suppl 1):S140-9

31. Lafage V, Smith JS, Bess S, Schwab FJ, Ames CP, Klineberg E, et al. Sagittal spino-pelvic alignment failures following three column thoracic osteotomy for adult spinal deformity. Eur Spine J. 2012;21(4):698-704. 